\title{
Imaginarios, violencia y sexismo entre cibernautas de tres sitios de noticias de Facebook en México ${ }^{1}$
}

\section{Imaginaries, violence and sexism among Internet users within three Facebook news sites in Mexico}

\author{
Norma Patricia Sepúlveda Logorreta (iD ${ }^{1}$, María Eugenia Flores Treviño (iD ${ }^{2}$ \\ 1 Universidad Autónoma de Coahuila, Coahuila, México. \\ patysep2003ayahoo.com.mx \\ 2 Facultad de Filosofía y Letras, Universidad Autónoma de Nuevo León, Nuevo \\ León, México. \\ maria.florestrauanl.edu.mx
}

\section{G ACCESO ABIERTO / OPEN ACCESS}

Cita: Sepúlveda Logorreta, Norma Patricia y Flores Treviño, Ma Eugenia (2019). Imaginarios, violencia y sexismo entre cibernautras de tres sitios de noticias de Facebook en México. Textos en Proceso, 5.2, pp. 61-74.

http://doi.org/10.17710/tep.2019.5.2.5 sepulvedaflores

Editors: Ariel Cordisco, Instituto de Lingüística, Universidad de Buenos Aires, Argentina; Ma Eugenia Flores Treviño, Universidad Autónoma de Nuevo León, México

Recibido: 20/02/2020

Aceptado: 10/05/2020

Conflicto de intereses: Los autores han declarado que no poseen conflicto de intereses.

Copyright: @ N.P. Sepúlveda Logorreta, M.E Flores Treviño. Esta obra está bajo licencia Creative Commons Reconocimiento 4.0

\section{Resumen}

Los espacios virtuales, dadas las características de la interacción que en ellos se desarrolla, ofrecen una relativa libertad o una sensación de permisividad con respecto a las normas de conducta establecidas en el nivel socio-cultural entre las personas. Dicha permisividad se puede observar en la violencia lingüística presente en las redes sociales. El objetivo de este trabajo es mostrar el empleo de ciertas estrategias descorteses que reproducen o promueven el discurso agresivo y la violencia verbal sexista en tres sitios de noticias con páginas en Facebook: Animal Político, Aristegui Noticias y Sin Embargo MX. Para ello se analizan 150 opiniones extraídas de noticias y que fueron motivadas por las expresiones de dos funcionarias públicas de la política mexicana hacia mujeres indígenas. Se desarrolla una aproximación sociopragmática y semiótico-discursiva para mostrar las actividades de imagen y las estrategias y recursos de que se valen los enunciatarios para ejercer el sexismo en esas plataformas. Las tendencias reflejan mayormente actos de descortesía: directa, indirecta y por refractariedad y el predominio de insultos y amenazas a la imagen de las funcionarias y las mujeres indígenas. Los actos de violencia sexista se realizaron exclusivamente hacía las funcionarias.

Palabras clave: imaginarios, violencia verbal, sexismo, discurso, Facebook.

\footnotetext{
${ }^{1}$ Esta es una investigación en desarrollo y pertenece al proyecto binacional "Descortesía y evaluación en comportamientos verbales sexistas dentro de las culturas rioplatense y mexicana" (URC-UANL, 2018).
} 


\section{Abstract}

The virtual spaces, given the characteristics of the interaction that takes place in them, offer a relative freedom or a sense of permissiveness with respect to the norms of conduct established at the socio-cultural level between people. This permissiveness can be observed in the linguistic violence present in social networks. The objective of this work is to show the use of certain discourteous strategies that reproduce or promote aggressive speech and sexist verbal violence in three news sites with pages on Facebook: Animal Politico, Aristegui Noticias and Sin Embargo $M X$. For this, 150 opinions extracted from the news are analyzed and were motivated by the expressions of two public officials of Mexican politics towards indigenous women. A sociopragmatic and semiotic-discursive approach is developed to show the image activities, strategies, and resources that enunciators use to exercise sexism on those platforms. The trends mostly reflect acts of discourtesy: direct, indirect and by refractoriness and the predominance of insults and threats to the image of civil servants and indigenous women. Acts of sexist violence were carried out exclusively against civil servants.

Keywords: social imaginary, verbal violence, discourse, Facebook.

\section{Introducción}

La violencia hacia las mujeres se suele ubicar en forma de golpes, puñaladas, disparos, asesinatos, actos que, por supuesto, son altamente violentos, pero, generalmente, no se llega a reconocer la violencia en un insulto o mensaje agresivo. Sin embargo, la violencia puede llevarse a cabo mediante actos de habla que pueden ser en extremo perjudiciales y con consecuencias sociales para las víctimas. En México la violencia verbal contra las mujeres también se manifiesta en las redes sociales. Considerando dicha violencia como una práctica usual en ellas, en este trabajo se analiza el empleo de ciertas estrategias descorteses con especial referencia al discurso agresivo y la violencia verbal sexista en tres sitios de noticias con páginas en Facebook: Animal Político, Aristegui Noticias y Sin Embargo MX.

En la comunicación que se desarrolla en los sitios de noticias de Facebook, es donde los comentaristas tienen la oportunidad de exponer su punto de vista sobre alguna noticia ahí publicada; en ocasiones ocurren actos descorteses que llevan a la violencia verbal sobre el sujeto referido o sobre otros comentaristas, especialmente cuando se convierten en arena política que fomenta la agresividad entre los participantes. Es suficiente la aparición de cualquier noticia polémica en estos espacios para que los usuarios utilicen las estrategias de acusar, insultar, calumniar, descalificar, atacar. Con ello se pretende lesionar la imagen social del referente central de la noticia -generalmente, un personaje público-, la del propio medio de comunicación, o la de otros usuarios que intervienen con sus opiniones.

Se reconoce que los textos en redes no solo se asientan en lo verbal y sus estrategias son multimodales. Esta investigación se enfoca en el recurso verbal y busca contribuir al análisis sobre la violencia lingüística de corte sexista en una red social como Facebook y sumarse a los estudios que existen al respecto en otras redes sociales. 


\section{Los sustentos de la aproximación}

Los intercambios que se desarrollan en ambientes virtuales se relacionan con comportamientos que los usuarios asocian con la posibilidad de expresar su opinión abiertamente, casi sin censura (López y González, 2013). Aunque Facebook es una plataforma útil para mantener conexiones sociales, también puede ser utilizado por los perpetradores de violencia contra las mujeres para llevar el abuso a este espacio virtual (Women's Health East, 2018).

Tanto Internet como las redes sociales se han convertido en fuertes potenciadores y reproductores de desigualdad. Las ideologías sexistas, como conjunto de creencias sobre los roles, características, comportamientos, etc., considerados apropiados para hombres y mujeres y la relaciones que ambos grupos deben mantener entre sí, pueden crear desigualdad de género dentro de las sociedades que no solo legitima el statu quo en las mismas, sino que también mejora activamente la rigidez de la jerarquía de género (Brandt, 2011). Por ello, la pregunta que guía este trabajo es: ¿con cuáles estrategias verbales se reproduce o promueve la violencia verbal sexista en los sitios de noticias seleccionados?

Las propuestas base para la investigación son la teoría de los actos de habla (Austin, 1963), que afirma que al hablar se realiza un tipo particular de acción. Para el estudio de la agresión y violencia verbal en el contexto virtual y del lenguaje en Internet consideramos las aportaciones de Fuentes y Alcaide (2008); Mancera (2009, 2014); Bañón (2010); Díaz (2014); Kaul de Marlangeon y Cordisco (2014); Vivas y Ridao (2015); Garza (2015); Campillo (2019); asimismo examinamos tanto los actos que amenazan la imagen (Brown y Levinson, 1987) como aquellos que la refuerzan (Kerbrat-Orecchioni, 2004). Sobre el tema del sexismo online empleamos las investigaciones de Fox, Cruz y Lee (2015) y Drakett, Rickett, Day y Milnes (2018). Para revisar el sexismo social y lingüístico, nos apoyamos en las propuestas de Expósito, Moya y Glick (1998), Glick y Fiske (1996); Glick, Sakali, Ferreira y Aguilar de Souza (2002); García Messeguer (1994, 1998); Moya (2004); Elche y Sánchez (2017), articulamos estas posturas con las Charaudeau (2009, 2011), Goffman (1967-1986) y Hernández Flores (2013) para estudiar las representaciones socio-discursivas y la imagen. Así integradas estas categorías nos permiten abordar lo que Amossy (2016) llama ethos previo o prediscursivo (que permite que el receptor se forme una idea del locutor antes de que se produzca el discurso) y revisarlo junto con el ethos propiamente discursivo.

\section{Agresión, violencia y descortesía}

Kaul de Marlangeon y Cordisco (2014) denominan descortesía al "comportamiento comunicativo que ataca, daña, denigra u ofende la imagen social del interlocutor; busca causarle un perjuicio o incide de manera negativa en el clima socio-emocional de la interacción" (Kaul de Marlangeon y Cordisco, 2014, p. 147). Por otro lado, Fuentes y Alcaide (2008), hacen una distinción entre agresividad y violencia verbal. Para las autoras, la agresión no persigue el daño propiamente sino afectar, como método disuasivo en la mayoría de las ocasiones; la violencia, por el contrario, persigue el daño, físico o psíquico, y tiene en el poder y las desigualdades sus aliados. En efecto, ya sea para agredir o violentar verbalmente, "recurrimos a estrategias de descortesía, buscando siempre que la imagen del otro se vea dañada en cierta manera" (Fuentes y Alcaide, 2008, p.18).

En la actualidad el fenómeno de la descortesía y violencia verbal se ha estudiado en el contexto de las redes sociales (Díaz, 2014; Kaul de Marlangeon y 
Cordisco, 2014; Campillo, 2019). Y es que, en la mayoría de los ejemplos caso analizados, la principal finalidad no es otra que la de vulnerar la imagen social (Goffman, 1967) del referente de su discurso. Para ello no se duda en ejecutar actos de habla que podrían calificarse como violentos (Campillo, 2019) con actitudes de prejuicio hacia las mujeres protagonistas de las noticias. Lo anterior se observa en el predominio de FTAs (face threatening acts) actos de amenaza de la imagen (Brown y Levinson, 1987) y escasas muestras de los llamados FFAs (face flattering acts) o actos de refuerzo de la imagen, propios de la cortesía valorizante (KerbratOrecchioni, 2004).

En cuanto al sexismo, en su amplia concepción original, se considera "una actitud dirigida hacia las personas en virtud de su pertenencia a los grupos basados en el sexo biológico, hombres o mujeres" (Expósito et al., 1998, p. 160). De forma más restringida, se entiende como una actitud de prejuicio hacia las mujeres (Moya, 2004). Para Glick y Fiske (1996), el sexismo se presenta de forma ambivalente porque está formado por dos componentes diferentes: el sexismo hostil y el sexismo benévolo. El primero ha sido conceptualizado como el resultado de las actitudes de clara antipatía y rechazo hacia las mujeres, sobre todo hacía aquellas que son percibidas como una amenaza para la superioridad o el dominio de los varones (feministas, profesionales). El segundo se basa en actitudes interrelacionadas hacia las mujeres que las consideran de forma estereotipada y limitada a ciertos roles (madre, esposa), pero que tiene un tono afectivo positivo de protección hacia ellas y de idealización como objetos amorosos.

De igual forma, Glick et al., (2002) analizaron la relación entre sexismo hostil y benévolo, de una parte, y las actitudes hacia la violencia de género, de otra. Con estudios en la población general de Turquía y Brasil, llegaron a la conclusión de que, el sexismo benévolo, aparentemente protector de las mujeres, no desempeña tal función cuando las mujeres desafían la autoridad del marido o violan los roles de género tradicionales. De allí que el sexismo hostil (y no el benévolo) se relacione con la justificación de la violencia hacia la esposa u otras mujeres. Por consiguiente, el sexismo crea un círculo vicioso en el cual a mayor hostilidad que las mujeres enfrentan de los hombres, más motivadas están para aceptar el sexismo benévolo, confiando en los miembros del grupo dominante (hombres) para protegerlas. Desafortunadamente, el respaldo de las mujeres a sexismo benévolo solo sirve para reforzar la desigualdad de género (Glick et al., 2002).

Con base en las aportaciones anteriores, en esta investigación se define al sexismo, o la ideología de género, como actitud ambivalente hacia las mujeres en donde la antipatía hostil coexiste con sentimientos positivos hacía las mujeres. Igualmente, se considera que los actos verbales violentos sexistas reflejan actitudes negativas en donde predomina el sexismo hostil que justifica la violencia lingüística hacia las mujeres que quebrantan los roles de género. Es decir, el sexismo y las actitudes sexistas forman parte de la justificación de la violencia (Moya y Lemus, 2007). El sexismo benévolo no desempeña aquí ninguna función y solo se muestra la cara más atroz de la violencia de género.

Cada vez existe más evidencia sobre cómo el lenguaje abusivo, personalizado, sarcástico y violento encontrado en un gran número de redes sociales, como Twitter (Mancera, 2014), Facebook (Vivas y Ridao, 2015) o YouTube, se dirige desproporcionadamente a las mujeres en comparación con los hombres (Fox et al., 2015; Drakett et. al., 2018). La violencia hacia las mujeres es constante en Internet y el sexismo ha sido identificado como un problema en blogs, 
foros en línea, sitios de redes sociales y videojuegos (Fox et al., 2015; Drakett et. al., 2018; Garza, 2015).

En el corpus seleccionado, las ideologías sexistas se construyen sobre imaginarios (Goffman, 1967, 1986; Charaudeau, 2009, 2011) generados a partir del discurso colectivo de las personas visitantes, quienes al amparo de la extimidad deseada para sí, ejercen la violencia verbal entre ellos materializada en lenguaje sexista y discriminatorio (García Meseguer, 1994, 1998).

\section{Estrategia metodológica y descripción de los datos}

\subsection{Estrategia metodológica}

Este acercamiento se desarrolló de manera interdisciplinaria considerando al acto de habla (Austin, 1963) como la unidad operativa, para localizar las acciones conflictivas en el corpus, así partimos desde una dimensión pragmática y, en la sociopragmática con Brown y Levinson (1987) revisamos los actos de imagen, que articulamos con la teoría de la imagen social (face), propuesta por Goffman (1967, 1986), al relacionar diversas categorías como las representaciones sociodiscursivas $^{2}$ (Charaudeau 2009), la incidencia del marco enunciativo sobre los interactuantes y del tercero (Kerbrat-Orecchioni y Plantin, apud Denis 1997; y Charaudeau, 2009) podemos acercarnos a la co-construcción (Arundale, 1999) de la imagen realizada entre los emisores de la nota y los comentaristas. En las actividades de imagen nos es útil la direccionalidad, propuesta por Hernández Flores (2013) $)^{3}$. También el concepto de modalidad que propone esta autora, relacionado con el tipo de efecto (positivo, negativo o neutro) que tiene ese comportamiento sobre la imagen, en este caso, tanto de quienes elaboran un discurso sexista, como de los posibles destinatarios de ese discurso. Luego revisamos con Kaul de Marlangeon (1995) la descortesía, en el continuo de la fuerza cortesía-descortesía que ella desarrolla. Así, transitamos desde la dimensión pragmática y sociopragmática, hasta la discursiva, que nos permite efectuar interpretaciones considerando el marco enunciativo-socio discursivo en que ocurre el intercambio.

\subsection{Sobre el corpus}

Se analizan 150 opiniones extraídas de tres sitios de noticias con páginas en Facebook: Animal Politico, Aristegui Noticias y Sin Embargo MX, para mostrar el empleo de ciertas estrategias descorteses con especial referencia al discurso agresivo y la violencia verbal sexista; la recopilación del corpus se ha realizado aleatoriamente, con base en la presencia de las marcas y vocablos de este tipo, y se han seleccionado opiniones motivadas por noticias que exhiben las expresiones de dos funcionarias públicas de la política mexicana hacia mujeres indígenas. Dichas expresiones de corte racista, principalmente, propiciaron también actos de violencia lingüística sexista por parte de algunos usuarios, tanto para las funcionarias, como para las mujeres indígenas, estas acciones son las que estudiamos aquí.

\footnotetext{
2 "Las representaciones pueden denominarse "sociodiscursivas" en función de que el proceso de configuración simbolizante del mundo se hace mediante sistemas de signos. Pero no por signos aislados, sino por medio de enunciados que significan los hechos y los gestos de los seres del mundo" (Charaudeau, 2011, p.13).

${ }^{3}$ Que se relaciona con quién es el hablante, el destinatario y otros posibles interactuantes, cuyas imágenes son afectadas por el comportamiento comunicativo y su efecto social.
} 
Los textos de las opiniones tienen un total de 6.652 palabras $^{4}$, de las cuales 2.316 corresponden a los textos de Animal Politico (AP) ${ }^{5}, 2.190$ a Aristegui Noticias (AN), y 2.146 a Sin Embargo MX (SEMX). En el cuadro 1 se describe la relación entre sitio de noticias y funcionaria pública con el número de opiniones y de palabras, así como la nomenclatura seleccionada para cada uno de ellos. El corpus queda establecido como mostramos en la Tabla 1:

Tabla 1. Distribución de las opiniones en tres sitios de noticias en Facebook

\begin{tabular}{|l|l|l|l|l|l|l|c|}
\hline \multirow{2}{*}{} & \multicolumn{2}{|c|}{$\begin{array}{c}\text { Animal Político } \\
\text { (AP) }\end{array}$} & \multicolumn{2}{c|}{$\begin{array}{c}\text { Aristegui Noticias } \\
\text { (AN) }\end{array}$} & \multicolumn{2}{c|}{$\begin{array}{c}\text { Sin Embargo MX } \\
\text { (SEMX) }\end{array}$} & Totales \\
\cline { 2 - 9 } & $(\mathbf{R R})^{6}$ & $(\mathbf{L S})$ & $\mathbf{( R R )}$ & $(\mathbf{L S})$ & $\mathbf{( R R )}$ & $(\mathbf{L S )}$ & \\
\hline Opiniones & 25 & 25 & 25 & 25 & 25 & 25 & 150 \\
\hline Cantidad de palabras & 1.857 & 459 & 1.324 & 866 & 1.439 & 707 & 6.652 \\
\hline
\end{tabular}

\section{Análisis de los datos}

\subsection{Actos de refuerzo y de amenaza de la imagen: funcionarias} públicas

La funcionaria federal, Rosario Robles ${ }^{7}$, ex titular de la $\operatorname{SEDESOL}^{8}$ y de la SEDATU ${ }^{9}$ visitó el día 30 de abril del 2014 el poblado serrano de Los Encinos, Nayarit, la cual es una región mexicana donde habitan las etnias coras, huicholes y tepehuanos. En el discurso que dirigió a dichas comunidades, mencionó que se quitarían los apoyos gubernamentales a las mujeres indígenas que tuvieran más de tres hijos porque usan la procreación para obtener más dinero. Por otro lado, la directora de INMUJER ${ }^{10}$ Tijuana, Liliana Rosas, publicó en su muro de Facebook, en febrero de 2015, una imagen con la nota: "Que tal si lo mío está en Europa y yo aquí sufriendo con estos indígenas".

Las expresiones de ambas funcionarias públicas, consideradas por muchos políticos y público en general como discriminatorias, aparecieron en los sitios de noticias aquí analizados. Ello motivó la aparición de opiniones agresivas y violentas, algunas con violencia sexista, que buscaron vulnerar la imagen de dichas funcionarias.

Un análisis cuantitativo del corpus muestra que la mayor parte de los usuarios realizaron FTAs (face threatening acts) o actos amenazantes a la imagen (Brown y Levison, 1987), y solo en contadas ocasiones se encontraron muestras de los actos de refuerzo de la imagen, los llamados FFAs (face flattering acts) propios de la cortesía valorizante (Kerbrat-Orecchioni, 2004). En la tabla 2 se resumen los resultados:

\footnotetext{
${ }^{4}$ La presentación numérica de las palabras tiene la finalidad de comparar en los tres sitios la cantidad de palabras que se utilizaron por noticia.

${ }^{5}$ En esta investigación, para facilitar su identificación, se diseñó una nomenclatura basada en la primera letra que compone el nombre de cada sitio de noticias.

${ }^{6}$ Para la nomenclatura de las funcionarias públicas se tomaron las iniciales de sus respectivos nombres: Rosario Robles (RR) y Liliana Sevilla (LS).

${ }^{7}$ Actualmente la funcionaria se encuentra en prisión preventiva justificada en el penal de Santa Martha, Ciudad de México, acusada del delito del ejercicio indebido de funciones que habría derivado en un desvío de 5.000 millones de pesos en las secretarias que dirigió.

${ }^{8}$ Secretaria de Desarrollo Social.

${ }^{9}$ Secretaría de Desarrollo Agrario, Territorial y Urbano.

${ }^{10}$ Instituto de la Mujer.
} 
Tabla 2. Análisis de la presencia de FTAs y FFAs

\begin{tabular}{|l|l|l|l|l|l|l|c|}
\hline & \multicolumn{2}{|c|}{$\begin{array}{c}\text { Animal Político } \\
\text { (AP) }\end{array}$} & \multicolumn{2}{c|}{$\begin{array}{c}\text { Aristegui Noticias } \\
\text { (AN) }\end{array}$} & \multicolumn{2}{c|}{$\begin{array}{c}\text { Sin Embargo MX } \\
\text { (SEMX) }\end{array}$} & Totales (\%) \\
\cline { 2 - 8 } & (RR) & (LS) & (RR) & (LS) & (RR) & (LS) & \\
\hline Predominan los FTAs & 24 & 24 & 24 & 25 & 22 & 24 & $\begin{array}{c}95,33 \% \\
(143 \text { opiniones) }\end{array}$ \\
\hline Predominan los FFAs & 1 & 1 & 1 & 0 & 3 & 1 & $\begin{array}{c}4,66 \% \\
\text { (7 opiniones) }\end{array}$ \\
\hline
\end{tabular}

Una gran mayoría de los actos amenazantes hacia la imagen de las funcionarias fueron dirigidos a dañar su prestigio social, por ejemplo, al utilizar críticas u ofensas destinadas al escarnio público. Ofrecemos resultados sobre una muestra de 53 segmentos extraídos de las 150 opiniones revisadas, los elegimos por contener acciones descorteses sexistas contra las mujeres.

\subsection{Actos de amenaza a la imagen de mujeres indígenas}

Los siguientes ejemplos muestran la violencia verbal que lleva a algunos usuarios a defender las decisiones de la funcionaria Rosario Robles y a degradar e insultar mediante la zoomorfización, pues comparan a las mujeres indígenas con animales (ej. 1). Al aludir a otros seres vivos como animales, se elabora una especie de genealogía constitutiva de lo inferior que aparece históricamente como antecedente natural de la constitución sustancial de los indígenas. En la asociación de la pobreza con las mujeres indígenas y con su forma de ser o de vivir (ejs. 1, 2, 3), se observa la articulación de la ideología sexista que considera a las mujeres como inferiores (Glick y Fiske, 1996) con otro discurso de dominación y desigualdad como el racismo:

1) SEMX (RR): “Te apoyo Rosario, pinches conejas indígenas, Guevones [sic], que se pongan a trabajar, mantenidas, [sic] viven de la gente que pagamos impuestos...!!!"”.

2) $\mathrm{AN}(\mathrm{RR})$ ¿Por qué es discriminatoria? Por decirles que no tengan más de tres hijos porque si no tienen para tragar ellas menos para darle de comer a sus veinte chamacos? Eso es un acierto, basta de seguir fabricando pobres y usar nuestros impuestos para alimentarlos.

3) AP (RR) Las mujeres indígenas ya encontraron su modus vivendi de ese tipo de programas sociales, en donde cada hijo les representa una renta mensual, un círculo vicioso que hay que cortar, apoyo total a que se limite el apoyo del estado.

A partir de lo anterior, es posible observar que las opiniones sobre los indígenas variaron e incluso presentaron contradicciones de acuerdo con las expresiones de las funcionarias públicas. En el caso de la noticia de Rosario Robles sobre el condicionamiento de los apoyos gubernamentales a las mujeres indígenas que tuvieran más de tres hijos, las opiniones con elementos discursivos agresivos hacia las indígenas se efectuaron con expresiones ofensivas y descalificadoras. Mientras que, en el caso de Liliana Sevilla, la violencia verbal se realizó hacia su persona y se valora positivamente a la figura del indígena como símbolo de identidad nacional relacionada con el pasado prehispánico y la ideología del mestizaje biológico cultural (ej. 4). Además, se señala a los indígenas como sujetos que pagan impuestos (ejs. 5 y 6) mientras que, como se pudo observar 
anteriormente, se les calificaba como sujetos "mantenidos" que viven de los impuestos de los demás:

4) $\mathrm{AN}$ (LSR): México necesita funcionarios comprometido con las personas vulnerables por que [sic]. [sic] en ellos están nuestras raíces y nuestro orgullo.

5) AN (LSR): Pero si quiere la lana de los indigenas [sic]. perra.

6) AP (LSR): Que se vaya a la chingada por pendeja! [sic] Estos indígenas le damos de tragar a la peladita esta!

La marcada presencia de groserías e insultos hacia la funcionaria con los adjetivos calificativos -"perra" y "pendeja"-, y apelativos que podrían calificarse como descorteses -"la peladita esta"-, muestra un tipo de lenguaje agresivo e incluso violento en los comportamientos sociales hacia las mujeres a nivel de una red social como Facebook. Lo anterior es importante considerando que interactuar con contenido sexista en línea de hecho puede continuar y fomentar actitudes sexistas fuera de línea (Fox, et al., 2015).

\subsection{Actos de amenaza a la imagen de mujeres indígenas}

El contexto virtual en que las funcionarias referidas fueron atacadas, dio lugar a que hubiera violencia verbal hacia ellas, hacia los indígenas referidos, hacia otras personas ajenas al conflicto y entre los mismos usuarios. El hecho de que la interacción se haya llevado a cabo en las redes originó una polifonía que brinda la oportunidad de atestiguar el flujo de posicionamientos ideológicos, culturales y sociales proyectados a partir del discurso. Como se muestra abajo; los actos de agresión son dirigidos a la imagen social de la funcionaria en cuestión (ejs. 7, 9 y 10), pero también se extienden hacia otras mujeres y hombres (ejs. 8 y 11):

7) AP (RR): Maldita zorra frigida [sic] seguro lo hace para robar más pinche vieja y como también debe estar malcogida se desquita con los indígenas quienes ojalá protesten en su contra!

8) AP (RR) Esto se acaba dando una vida digna a estas personas! Y porque indígenas caray! Si no tan lejos en las mismas colonias de las ciudades grandes viven mujeres con 4 o 5 chamacos de diferentes padres! Y las viejas flojas no trabajan viven de las demandas a los padres de los chiquillos...EDUCACIÓN es lo que necesitamos!!!

9) SEMX (LSR) No sirve para el puesto que desempeña, esta [sic] claro. Debería lavar mis baños, para eso si se ve buena, porque si no tiene ni idea de las funciones que debe desempeñar en ese cargo, menos ha de saber de arte.

10) SEMX (LSR) Noooo por favor, a ver dónde se firma para que la separen del cargo, por racismo clasista y faltas a los derechos humanos? Tienen todo para superarse y buscar una mejor calidad de vida. Y si alguien puede decirle a ella que se quede en su casa lavando platos, haciendo quehacer, educando a sus hijos y atendiendo a su marido... "no la veo haciendo otra cosita".

11) AP (RR) La ignorancia y el machismo han permitido que en México las parejas sean "unión de pelados, fábrica de encuerados" $\mathrm{y}$, potencialmente criminales porque están al margen del progreso.

Igualmente, los comentaristas sustentan sus ofensas en argumentos relativos a la sexualidad (ejs. 11, 12 y 15) ya sea por falta de ella ("malcogida"), por poseer múltiples parejas ("chamacos de diferentes padres") o por machismo e ignorancia 
("unión de pelados, fábrica de encuerados") y también emplean otros mecanismos de validación (ej. 13 y 14) que se refieren al rol tradicional de la mujer asociados a las tareas domésticas ("debería lavar mis baños", "lavando platos, haciendo quehacer... atendiendo a su marido").

Otras opiniones ilustran de forma clara el tipo de contenido hacia las dos funcionarias públicas como actos verbales violentos sexistas:

12) AN (RR): "Pobre India ladina, igualita que Elba Gordillo, deberían lincharlas, su discriminación solo representa su ignorancia, [sic] Espero se haga justicia y no dejen pasar este asunto al olvido".

13) AN (LSR): "Maldita hija de su puta madre de mis impuestos traga y viste cuando la vea $l o[\mathrm{sic}]$ voy a violar perra desgrasiada [sic]".

14) AN (LSR): “Q[sic] la linchen por Racista y discriminar a SU propia gente. ¡FUERA! [sic]".

15) SEMX (LSR): "Que la cuelguen por racista ja ja es broma pero si [sic] se paso [sic] entonces mejor que se vaya a Europa tal ves [sic] le valla [sic] mejor :v".

Se observa que fue significativa la presencia de enunciados en donde predomina el sexismo hostil que fomenta el acoso sexual y la violación (ej. 13), así como otras formas de violencia física como el linchamiento y la horca (ejs.12, 14, 15). Aquí el sexismo hostil, al aplicarse a mujeres que quebrantaron los roles de género, profesionistas que ocupan un cargo público, justifica las actitudes hacia la violación, el asesinato tumultuario o el castigo, la violación como violencia individual, linchamiento como violencia colectiva y el ahorcamiento como pena de muerte.

Asimismo, revisamos las actividades de descortesía de la muestra con sustento en las aportaciones de Kaul de Marlangeon (1995, 2005). Hemos utilizado sus categorías referidas a la causa, propósito, tipo y escala de la descortesía (2005, pp. 299-318) que aparece en las manifestaciones verbales de los cibernautas. Se observan los resultados en la tabla 3 :

Tabla 3. Causa, propósito y tipo de los actos descorteses voluntarios

\begin{tabular}{|l|c|}
\hline CAUSA & Frecuencia \\
\hline Deseo de lesión de la imagen de OC: & 6 \\
\hline Deseo de lesión de la imagen de SR: & 48 \\
\hline Deseo de lesión de la imagen de C: & 2 \\
\hline PROPÓSITO & 1 \\
\hline defensivo de la imagen de OC: & 21 \\
\hline defensivo de la imagen de SR: & 8 \\
\hline defensivo de la imagen de C: & \\
\hline TIPO & 44 \\
\hline Escatima deliberada de cortesía: & 6 \\
\hline Ofensa con propósito lesivo a la imagen de OC: & \\
\hline
\end{tabular}

Según los hallazgos que se muestran en la Tabla 3, entre las causas de la descortesía, el deseo de lesión de la imagen del $\mathrm{SR}^{11}$ (las funcionarias) fue la más frecuente (48); mientras que el daño a la imagen de $\mathrm{OC}^{12}$ solo se manifestó 6 veces

\footnotetext{
${ }^{11}$ Sujeto Referido.

${ }^{12}$ Otro Comentarista.
} 
y la agresión al $\mathrm{C}^{13}$ solamente se presentó en 2 ocasiones. En lo que respecta al propósito que motivó las agresiones, la defensa del SR (en este caso, la población indígena) aparece con 21 frecuencias, luego encontramos 8 recurrencias para la defensa de $\mathrm{C}$, y solamente $1 \mathrm{vez}$ se defendió a OC. En relación con el tipo de descortesía, hallamos 44 casos en que es intencional la estrategia de la agresión, y 6 manifestaciones para ofender a OC. En suma, los comentarios aspiraron a lesionar la imagen de las funcionarias y lo hicieron empleando intencionalmente recursos descorteses (67\% de frecuencias de aparición), al mismo tiempo que deseaban defender a los indígenas ( $15 \%$ de frecuencias), sobre los cuales se discutían sus derechos.

Sin embargo, en ocasiones, al agredir a la enunciataria, las ofensas incluían a terceras personas o entidades, aquí la direccionalidad de las actividades de imagen (Hernández Flores, 2013) se presentó en dos sentidos, con efecto positivo para unos sujetos referidos, pero negativo para otros:

16) Ha [sic] muchacha tan lokita[sic]. Gúerita [sic] de rancho ${ }^{14}$ si no fuera por los indígenas qué comería.

17) guera [sic] de rancho de seguro su madre es indígena.

Como se observa, hay una intención de defender a los indígenas, pero se ofende a otras comunidades; incluso, a los mismos indígenas, como en el ejemplo 17.

En la Tabla 4 se muestran los datos sobre la descortesía involuntaria, los resultados del tipo de descortesía empleada en los comentarios fueron más frecuentes para la escatima de cortesía ( 28 casos), así como para la carencia de cortesía (27 ocurrencias):

Tabla 4. Actos descorteses involuntarios

\begin{tabular}{|l|c|}
\hline TIPO & Frecuencia \\
\hline Ofensa con propósito defensivo de la imagen de C & 8 \\
\hline Metedura de pata & 8 \\
\hline Escatima de la cortesía esperada & 28 \\
\hline Ausencia de cortesía & 27 \\
\hline
\end{tabular}

De la misma forma, los locutores prefirieron no brindar la cortesía esperada (47 frecuencias), así como, sin desearlo, cometieron actos descorteses (16 frecuencias) cuando intentaban lo contrario. Los cibernautas fueron descorteses, contrariando su propósito de defensa del indígena en 9 ocasiones, y en 2, lesionaron su propia imagen. Exponemos los datos en la tabla 5:

Tabla 5. Escala de la descortesía

\begin{tabular}{|l|c|}
\hline ESCALA & Frecuencia \\
\hline Acto formalmente descortés/propósito cortés & 16 \\
\hline Acto descortés involuntario & 9 \\
\hline Auto-descortesía & 2 \\
\hline Escatima deliberada de cortesía & 47 \\
\hline
\end{tabular}

\footnotetext{
${ }^{13}$ Comentarista.

${ }^{14}$ En México, existe discriminación por la gente de origen rural, se les llama "de rancho" y, a quienes tienen pelo claro: "güeros/as".
} 
En cuanto se refiere a la intensidad de los actos descorteses, se manifestaron descortesías de fustigación ${ }^{15}$, en su modalidad de refractariedad ( 21 frecuencias), y predominó la tendencia hacia la afiliación exacerbada (31 frecuencias) por la defensa de los indígenas, ello indica un alto nivel de violencia, ya que los usuarios, en su mayoría, buscaron generar el conflicto. Las respuestas de los cibernautas se orientaron a la defensa (10 frecuencias) de los indígenas, al ataque (16 frecuencias) hacia la imagen de las funcionarias y al contraataque (27 frecuencias) orientado o bien a defender/atacar a las mujeres y familias indígenas o bien al público; estos actos tuvieron un doble blanco: tanto las funcionarias, como terceras personas o comunidades.

De acuerdo con Bolívar (2001), los insultos resultan en una descortesía, que los hablantes usan para crear conflicto intencionalmente y alimentarlo -en este caso- en el flujo de la interacción virtual; el propósito, como indica la autora, es desautorizar o aniquilar al oponente como un interlocutor válido para la disputa, ello trasciende la finalidad de "herir", porque impide el diálogo (por tanto, la defensa), al no existir una entidad para dialogar.

\section{Conclusiones}

En un primer momento, el análisis cuantitativo de 150 opiniones de los lectores de los tres sitios de noticias con páginas en Facebook nos ha permitido observar en ellos un claro predominio de actos de amenaza de la imagen, en comparación de los actos de refuerzo de la imagen propios de la cortesía valorizante, mucho más escasos. Los usuarios utilizaron los FTAs, por ejemplo, para atentar contra la imagen social de las funcionarias públicas y de las mujeres indígenas que protagonizaron la información noticiosa.

Al considerar que desde la sociopragmática se llega a tomar el pulso a la sociedad, por cuanto que la utilización de una lengua funciona como reflejo de los comportamientos sociales de los individuos (Halliday, 2001), los resultados obtenidos muestran la presencia de un alto grado de comportamiento descortés, agresivo y violento hacia las protagonistas de las notas.

Los usuarios, al hacer uso de la violencia verbal por medio de insultos, descalificaciones, o incluso bromas, buscan afianzar el vínculo con los receptores que comparten sus mismas opiniones, es decir, se afilian entre ellos. La tendencia hacia los insultos se debe, principalmente, al anonimato - lo cual les da una gran libertad pues pueden expresarse sin afectar su propia imagen social-y a la ausencia de copresencia física entre los interactuantes en estos contextos virtuales.

La teoría del sexismo ambivalente fue significativa al considerar no solo a un conjunto de actitudes negativas hacia las mujeres, sino todo un mecanismo de dominio presente en las sociedades donde se privilegia a los varones, y tiene como fin perpetuar el control masculino sobre las principales instituciones sociales. El sexismo, como ideología creada para mantener los privilegios del grupo dominante y que comparten hombres y mujeres, contribuye al mantenimiento del statu quo, esto es, a que se perpetúe la situación de subordinación y de subyugación de las mujeres como grupo.

Hemos visto cómo la violencia se presenta en todas sus gradaciones y, confirmamos como ya lo habíamos enunciado (Flores, 2016) que, en México

${ }^{15}$ Es un tipo de descortesía que está constituida "por comportamientos volitivos, conscientes y estratégicos, destinados a herir la imagen del interlocutor; para responder a una situación de enfrentamiento o desafío, o con el propósito de entablarla" (Kaul de Marlangeon, 2005, p. 302). 
cuando se dirige a la mujer, dichos actos están construidos con base en: su actividad sexual; la fecundidad femenina como función social; las labores domésticas que son desempeñadas por las mujeres; la actividad sexual como medio de intercambio; la dominación sexual; la cosificación y una asimetría y subalternidad esencial con respecto al varón. En menor número, pero no por ello menos importante, se encontraron ejemplos de actos verbales violentos sexistas en donde predominó el sexismo hostil como precursor de la justificación de la violencia de género. Añadiríamos a esos resultados que no importa el género o el posicionamiento social de los y las enunciadores/as que efectúan la agresión o violencia, pues utilizan frecuentemente esos sustentos ideológico-culturales para elaborar los recursos discursivos de la agresión.

Lo que podemos leer en las redes es solo el reflejo de la manera en que nos relacionamos entre nosotros y eso es lo que tenemos que cambiar. Es de suma importancia crear formas más equitativas de relación entre hombres y mujeres, así como tratar de eliminar en nuestra sociedad el mecanismo de transmisión generacional de la inferioridad de la mujer para disminuir y eventualmente erradicar el desarrollo de futuras ideas sexistas (Elche y Sánchez, 2017). Lo que hacen las redes como Facebook es visibilizar nuestros imaginarios. El sexismo o el racismo estaban antes de que tuviéramos nombres asociados a una cuenta en esta plataforma. Lo que ocurre es que nunca había sido tan fácil saber qué pasaba por la mente de millones de personas. De esta forma, se pudo observar cómo la opresión que estructura la violencia de género en el "mundo real" se ha filtrado en los términos léxicos que se utilizan en esta red social y que reconfiguran el entorno virtual.

\section{Referencias}

1. Amossy, R. (Coord.) (2016). Imagens de Si no Discurso: a construção do ethos. São Paulo: Contexto.

2. Arundale, R. (1999). An alternative model and ideology of communication for an alternative to politeness theory. Pragmatics, 9(1), pp. 119-153. https://doi.org/10.1075/prag.9.1.07aru

3. Austin, J. (1963). Cómo hacer cosas con palabras. Barcelona: Paidós.

4. Bañón, A. N. (2010). Comunicación destructiva y agresividad verbal en la Red. Discurso y Sociedad, 4(4), pp. 649-673.

5. Brandt, M. J. (2011). Sexism and Gender Inequality Across 57 Societies. Psychological Science, 22(11), pp. 1413-1418. https://doi.org/10.1177/0956797611420445

6. Bolívar, A. (2001). El insulto como estrategia en el diálogo político venezolano. Oralia, 4, pp. 47-73.

7. Brown, P. y Levinson, S. (1987). Politeness. Some universals in language. Cambridge: Cambridge University Press.

https://doi.org/10.1017/CBO9780511813085

8. Campillo, A. (2019). Propuesta de clasificación de actos verbales violentos en las redes sociales. E-Aesla, 5, pp. 199-207.

9. Charaudeau, P. (2009). Tercero ¿dónde estás? A propósito del tercero en el discurso, en Montes, R., y Charaudeau, P. (Coords.). El "tercero". Fondo y figura de las personas del discurso (pp. 17-44). Puebla: Benemérita Universidad Autónoma de Puebla.

10. Charaudeau, P. (2011). Las emociones como efectos de discurso. Revista Versión (Vol. La experiencia emocional y sus razones), 26, pp. 97-118.

11. Denis D. (1997). Reseña a Le Trilogue, dirigido por Kerbrat-Orecchioni, C. y Plantin, C., Lyon: Presses universitaires de Lyon (1995), L'Information 
Grammaticale, 73, pp.61-62. Recuperado de:

<http://www.persee.fr/doc/igram_0222-

9838_1997_num_73_1_2934_t1_0061_0000_7>.

12. Díaz, J. C. (2014). Creatividad léxica y descortesía en los medios de comunicación virtual. Revista de Filología, 32, pp. 81-97.

13. Drakett, J., Rickett, B., Day, K. y Milnes, K. (2018). Old jokes, new media Online sexism and constructions of gender in Internet memes, Feminism \& Psychology, 28(1), pp. 109-127. https://doi.org/10.1177/0959353517727560

14. Elche, M. y Sánchez, A. (2017). Actitudes sexistas y construcción de género. Itinerario de lectura para la igualdad. Revista de Educación Social, 24, pp. 524-532.

15. Expósito, F., Moya, M. y Glick, P. (1998). Sexismo ambivalente: medición y correlatos. Revista de Psicología Social, (13)2, pp. 159-169. Recuperado de: https://www.uv.es/ friasnav/LecturaCompl1.pdf https://doi.org/10.1174/021347498760350641

16. Flores, M. E. (2016). Violencia, género y sexismo. Una muestra de estrategias argumentativas en el discurso político mexicano. En Fuentes Rodríguez, C. (Ed.) Estrategias argumentativas y discurso politico (pp. 75105). Madrid: Arco Libros,

17. Fuentes, C. y Alcaide, E. (2008). (Des)cortesía, agresividad y violencia verbal en la sociedad actual. Sevilla: Universidad Internacional de Andalucía.

18. Fox, J., Cruz C. y Lee J. Y. (2015). Perpetuating online sexism offline: Anonymity, interactivity, and the effects of sexist hashtags on social media. Computers in Human Behavior, 52, pp. 436-442. https://doi.org/10.1016/j.chb.2015.06.024

19. García Meseguer, Á. (1994). ¿Es sexista la lengua española? Una investigación sobre el género gramatical. Barcelona: Paidós.

20. García Meseguer, Á. (1998). Lenguaje y discriminación sexual. Barcelona: Montesinos.

21. Garza, C. (2015). Discurso de odio y redes sociales: algunas elucubraciones. En: Casas Chousal, Y. (Coord.) Mensajes de discriminación y odio en redes sociales (pp. 105-118), México: CONAPRED.

22. Glick, P. y Fiske, S.T. (1996). The Ambivalent Sexism Inventory: Differentiating hostile and benevolent sexism. Journal of Personality and Social Psychology, 70(3), pp. 491-512. https://doi.org/10.1037/0022-3514.70.3.491

23. Glick, P., Sakali, N., Ferreira, M. C. y Aguiar de Souza, M. (2002). Ambivalent sexism and attitudes toward wife abuse in Turkey and Brazil. Psychology of Women Quarterly, 26, pp. 292-297.

24. Goffman, E. (1967). Interaction Ritual. New York: Doubleday.

25. Goffman, E. (1986). Frame analysis, an essay on the organization of experience. Northeastern: Northeastern University Press.

26. Halliday, M. A. K. (2001). El lenguaje como Semiótica social. La interpretación social del lenguaje y su significado. México: Fondo de cultura Económica.

27. Hernández Flores, N. (2013). Actividad de imagen: caracterización y tipología en la interacción comunicativa. Pragmatica socioculural, 1(2), pp. 175-198. https://doi.org/10.1515/soprag-2012-0012

28. Kaul de Marlangeon, S. (1995). La fuerza de cortesía-descortesía y sus estrategias en el discurso tanguero de la década del '20. RASAL, 3(3): pp. 738. Recuperado de: http://www.edice.org/descargas/SKaul.pdf

29. Kaul, de Marlangeon, S. (2005). Descortesía de fustigación por afiliación exacerbada o refractariedad. En Bravo, D. (Ed.), Estudios de la (des)cortesía en español. Categorías conceptuales y aplicaciones a corpora orales y escritos (pp. 299-318), Buenos Aires: Dunken. 
30. Kaul de Marlangeon, S. B. y Cordisco, A. (2014). La descortesía verbal en el contexto político-ideológico de las redes sociales. Revista de Filología, 32 , pp. 145-162.

31. Kerbrat-Orecchioni, C. (2004). ¿Es universal la cortesía?. En: Bravo, D. y Briz, A. (Eds.) Pragmática sociocultural: estudios sobre el discurso de cortesía en español (pp. 39-53), Barcelona: Ariel.

32. López Ireta, T. L. y González Arias, C. (2013). Las expresiones agresivas en los comentarios de los usuarios de blogs periodísticos: un análisis por medios de la teoría de la valoración. Tonos Digital. Revista de Estudios Filológicos, 24. Recuperado de: http://hdl.handle.net/10201/35788

33. Mancera, A. (2009). Manifestaciones de descortesía y violencia verbal en los foros de opinión digitales de los discursos españoles. Discurso y Sociedad, 3(3), pp. 437-466.

34. Mancera, A. (2014). El sexismo como blanco de humor en las redes sociales. Feminismo/s, 24, pp. 163-192.

35. Moya, M. (2004). Actitudes sexistas y nuevas formas de sexismo. En Barberá, E. y Martínez, I. (Coords.). Psicología y Género (pp. 271-294). Madrid: Pearson Educación.

36. Moya, M. y Lemus, S. de (2007). "Puño de hierro en guante de terciopelo". Diferencias de poder, sexismo y violencia de género. En: Yubero, $\mathrm{S}$., Larrañaga, E., y Blanco, A. (Dirs.) Convivir con la violencia (pp. 99-116). Cuenca: Servicios Publicaciones UCLM.

37. Vivas, J. y Ridao, S. (2015). "Lo siento pero me parecen horribles!!!": análisis pragmalingüístico de la descortesía en la red social Facebook. Revista de Filología, 33, pp. 217-236.

38. Women's Health East (2018). Women online: The intersection of technology, gender and sexism. Melbourne: WHE. 